Original Article

\title{
PIPER CHABA EXTRACTS WITH ANTIBIOFILM ACTIVITY INFLUENCE ANTIHYPERGLYCEMIC AND ANTIHYPERLIPIDEMIC RESPONSES IN DIABETIC WISTER RATS
}

\author{
SULTANA RAJIA ${ }^{1}$, KHADIZA KHANAM², UMME FARHANA ${ }^{2}$, SOHANUR RAHMAN², RASHIDUL HAQUE ${ }^{*}$ \\ ${ }^{1}$ Center for Interdisciplinary Research (CIR), Varendra University, Rajshahi, Bangladesh, ${ }^{2}$ Department of Pharmacy, Faculty of Science and \\ Engineering, Varendra University, Rajshahi, Bangladesh \\ Email: rhaque2011@gmail.com \\ Received: 01 May 2021, Revised and Accepted: 07 Jul 2021
}

ABSTRACT

Objectives: Piper chaba, native to South and Southeast Asia, has been traditionally used as a medicinal plant. Aim of this study was to evaluate the antihyperglycemic and antihyperlipidemic activities of $P$. chaba root extracts (RE) in streptozotocin (STZ)-induced diabetic rats along with its antimicrobial activity.

Methods: Diabetes was induced in Wister rats through the intraperitoneal administration of STZ (50 mg/kg b.w.). Antidiabetic and antilipidemic activities of the RE (in methanol, ethanol, ethyl acetate and distilled water) were evaluated by administering oral dose (200 mg/kg b.w.) for $21 \mathrm{~d}$. Metformin (12.1 mg/kg b.w.) was used as a positive control. Blood samples of rats were drawn by tail vein puncture and cardiac puncture to determine the fasting blood glucose (FBG) and serum level of total cholesterol (TC), triglycerides (TG), low-density lipoprotein (LDL), and highdensity lipoprotein (HDL), respectively. Standard protocols were followed to determine the antimicrobial and antibiofilm activities against two different strains of bacteria.

Results: Oral administration of $P$. chaba RE for 21 d resulted in a significant $(\mathrm{p}<0.001$ ) decrease in FBG and TC, TG, and LDL levels ( $<<0.001$ ), when compared to the untreated diabetic rats. Significant $(\mathrm{p}<0.001)$ increase of HDL was observed when ethyl acetate and aqueous RE were administered. Out of four, two extracts showed varying antimicrobial activities, particularly against the gram-positive bacteria.

Conclusion: It became evident for the first time that $P$. chaba extracts possess antimicrobial activities and can serve as biochemical compounds with great alternative therapeutic potential in the management of diabetes and hypercholesterolemia.

Keywords: Piper chaba, Antidiabetic, Antilipidemic, Antibiofilm

(C) 2021 The Authors. Published by Innovare Academic Sciences Pvt Ltd. This is an open access article under the CC BY license (https://creativecommons.org/licenses/by/4.0/) DOI: https://dx.doi.org/10.22159/ijpps.2021v13i9.41950. Journal homepage: https://innovareacademics.in/journals/index.php/ijpps.

\section{INTRODUCTION}

In Bangladesh, four hundred and forty nine species of medicinal plants have been enlisted so far [1]. Among them, Piper chaba is a vine in the family of Piperaceae. It is found in the South Western region of Bangladesh, particularly at Jashore and Khulna regions, and people use it as an additive spice. Extracts of $P$. chaba possess phenolic compounds, antioxidants and showed anti-inflammatory, cytotoxic and anti-bacterial properties $[2,3]$. Also, phytochemicals isolated from plants of the Piper species showed anticancer properties $[4,5]$.

Medicinal plants are of considerable interest to researchers in recent years to treat diabetes mellitus [6]. Diabetes mellitus (DM) is a group of chronic, complex metabolic disorder characterized by hyperglycemia due to defects in insulin production, insulin secretion, and insulin signaling [7]. Insulin is a potent hormone that regulates blood glucose level [8]. Globally, diabetes is the leading cause of human death. According to International Diabetes Federation (IDF), an estimated 463 million people, as of 2019, had diabetes worldwide ( $8.8 \%$ of the adult population), with type 2 diabetes making up about $90 \%$ of the cases [9]. According to the latest World Health Organization (WHO) data, DM-induced death reached to 28,065 or $3.61 \%$ of total deaths in Bangladesh [10]. Diabetes and hyperlipidemia are two factors responsible for the development of cardiovascular diseases. They have severe effect on lipid metabolism and show atypical effect on total lipid profile. Retinopathy, cardiovascular diseases, polyurea, polyphasia result from long time uncontrolled diabetes [11]

Besides insulin, the most widely used oral hypoglycemic drugs are Insulin sensitizer, insulin secretagogues, a-glucosidase inhibitors, and dipeptidyl peptidase-4 inhibitors. But those drugs have remarkable toxicity and side effects [12]. On the contrary, the traditional medicines prepared from herbal plants containing phenolic compounds having antidiabetic activity are cost effective with fewer side effects [13]. Also, WHO has been encouraging the use of traditional medicine to treat life threatening diabetes as well as it's complications [14].

Plants of the Piperacae family (such as $P$. betle, $P$. crocatum, $P$. longum, $P$. nigrum and $P$. sarmentosum) have been reported for their antidiabetic activities. Mixture extracts of $P$. crocatum leaves and Cinnamomum burmannii bark was reported to enhance the number of pancreatic $\beta$ cells in rats, increase the rats' blood insulin levels, and reduce the rats' blood glucose levels [15]. Also, aqueous RE of $P$. longum was found to significantly decrease the hyperglycemic and hyperlipidemic activities in STZ-induced diabetic rats [16] Additionally, in another study, aqueous extract of $P$. nigrum seeds and Vinca rosea flowers treatments lead to significant lowering of blood sugar level and reduction in serum lipids [17].

However, the literature review shows that there has been no study on the effects of $P$. chaba RE on STZ-induced rats to evaluate their antidiabetic and antihyperlipidemic activities. Hence, this study was undertaken to investigate these activities of $P$. chaba REs in induced diabetic rats.

\section{MATERIALS AND METHODS}

Collection of samples and preparation of extracts

Dry roots of $P$. chaba were purchased from the local market of Khulna, Bangladesh. Identification and authentication of the plant material were confirmed at the Department of Botany, University of Rajshahi, Bangladesh.

The sample was powdered using mortar and pestle. $250 \mathrm{gm}$ of the powder was accurately weighed and separately dissolved with 
methanol $(\mathrm{MeOH})$, ethanol $(\mathrm{EtOH})$, ethyl acetate (EtOAc) and distilled water (Aqueous, AQ), taking $1500 \mathrm{ml}$ solvent and stirred for $72 \mathrm{~h}$. It was then filtered and the filtrate was concentrated using a rotary evaporator (RE-401, Stuart equipment, Staffordshire, UK) at $30^{\circ} \mathrm{C}-40$ ${ }^{\circ} \mathrm{C}$. The yield percentages were calculated using the following formula: Extract yield $(\%)=\mathrm{R} / \mathrm{S} \times 100$ (where R; weight of extracted plant residues and S; weight of the plant raw sample) [18]. The yield of EtOAc, $\mathrm{MeOH}, \mathrm{EtOH}$ and $\mathrm{AQ}$ extracts were $28 \%, 12 \%, 20 \%$ and $25 \%$ $\mathrm{w} / \mathrm{w}$, respectively. The extracts were stored in small bottles at $4{ }^{\circ} \mathrm{C}$.

\section{Chemicals/reagents/diagnostic kits}

The antidiabetic drug, metformin was obtained as a gift sample from Incepta Pharmaceuticals Ltd, Savar, Dhaka, Bangladesh. STZ (Sisco Research Laboratories Pvt. Ltd. India) and glucose standard strip/kits, and glucometer (GlucoxTD-4183 Blood glucose test strips, Germany). All other chemicals and reagents used were of analytical grade.

\section{Experimental animals and ethical permission}

Three-month old healthy male Wister albino rats (180-220 gm body weight) collected from the Pharmacology Lab, Department of Pharmacy, Jahangirnagar University, Dhaka, Bangladesh. This investigation was officially recognized by the Ethical Review Committee, Varendra University, Rajshahi, Bangladesh. Rats were kept in polypropylene cages group wise, 6 animals per cage. Before the experiment, the animals were synchronized to the experimental/ laboratory condition for $7 \mathrm{~d}$. The ambient temperature, humidity and $12 \mathrm{~h}$ day-night cycles were maintained according to the animal care and welfare guidelines [19]. All the animals were allowed to have a free access to fresh pellet diet and water.

\section{Distribution of experimental animals in groups}

For the evaluation of different extracts on the hyperglycemic and hyperlipidemic activities in normal and STZ-induced animals, adult male Wister rats were divided into 7 groups with six rats in each and treated with four different $P$. chaba extracts by gastric intubation via oral cavity:

\section{Group-1: NDC-Non-diabetic control rats treated with standard diet}

Group-2: DC-STZ-induced diabetic rats treated with standard diet (negative-control group)

Group-3: D+Metformin-Diabetic rats treated with standard diet and metformin (12.1 mg/kg b.w. in a day) (positive control group)

Group-4: D+EtOH-Diabetic rats treated with standard diet and ethanol extracts $(200 \mathrm{mg} / \mathrm{kg}$. b.w. in a day)

Group-5: D+MeOH-Diabetic rats treated with standard diet and methanol extracts $(200 \mathrm{mg} / \mathrm{kg}$. b.w. in a day)

Group-6: D+EtOAc-Diabetic rats treated with standard diet and ethyl acetate extracts $(200 \mathrm{mg} / \mathrm{kg}$. b.w. in a day)

Group-7: D+AQ-Diabetic rats treated with standard diet and aqueous extracts ( $200 \mathrm{mg} / \mathrm{kg}$. b.w. in a day).

\section{Induction of diabetes and test for antidiabetic study}

A single dose of $50 \mathrm{mg} / \mathrm{kg}$ b.w. of STZ was prepared with $0.01 \mathrm{M}$ citrate buffer ( $\mathrm{pH}$ 4.5). Then the freshly prepared solution was administered intraperitoneally to each experimental rat. After $48 \mathrm{~h}$, rats with the fasting blood glucose (FBG) level of $200 \mathrm{mg} / \mathrm{dl}$ were selected as diabetic rats and were used for the study. The extracts were orally administered for $21 \mathrm{~d}$ once a day. On the $21^{\text {st }}$ day, the blood sample was collected from the tail vein of rats and the FBG level was measured using one-touch glucometer (GlucoxTD-4183 Blood glucose test strips, Germany) with glucose oxidaseperoxidase reactive strips.

\section{Measurement of serum lipid profile}

At the beginning of the experiment, animals were deprived of food overnight. The animals were anaesthetized with chloroform and two milliliters of fasting blood samples was obtained from each animal of both the control and test groups via cardiac puncture. The blood sample was collected into a tube containing lithium heparin as anticoagulant. The serum obtained after centrifugation at 3500 RPM for $15 \mathrm{~min}$ was separated for lipid measurement. The serum concentration of total cholesterol (TC), triglycerides (TG), high density lipoprotein (HDL)-cholesterol and low density lipoprotein (LDL)-cholesterol were measured using UV-spectrophotometric methods. Laboratory kit reagents (Human, Wiesbaden, Germany) following the company's instruction were used for all biochemical analysis and the absorbance was read using a UV-Vis spectrophotometer (Shimadzu UV-1280, Kyoto, Japan).

\section{Formation of zone of inhibition in disc diffusion assay}

Evaluation of the antimicrobial activity of all four Piper chaba root extracts was determined against Bacillus cereus (gram positive) and Escherichia coli (gram negative) by disc diffusion method [20]. Each bacterial strain was subcultured overnight at $37^{\circ} \mathrm{C}$ in Mueller-Hilton agar slants. The bacteria were harvested using $5 \mathrm{ml}$ of sterile saline water. Its absorbance was adjusted at $580 \mathrm{~nm}$ by a spectrophotometer and diluted to attain a viable cell count of $10^{7} \mathrm{CFU} / \mathrm{ml}$. Filter paper discs were loaded with Piper chaba stem extract at concentrations of $200 \mu \mathrm{g} / \mathrm{disc}$ and $400 \mu \mathrm{g} / \mathrm{disc}$. The plates were kept in the fridge at $4{ }^{\circ} \mathrm{C}$ for $2 \mathrm{~h}$. to permit the diffusion of plant extract. After incubating at 37 ${ }^{\circ} \mathrm{C}$ for $24 \mathrm{~h}$, presence of inhibition zones were measured by a transparent scale in $\mathrm{mm}$ and recorded as well.

\section{Determination of antibiofilm activity}

Formation of biofilm biomass was determined through the microtiter plate assay in 96-well polystyrene flat bottom plates [20]. After overnight cultures of $E$. coli, optical density (OD) 1.0 was determined at $600 \mathrm{~nm} .1 \%$ test microbes was mixed with $1 \mathrm{ml}$ of immediately prepared LB media with or without the ethyl acetate and methanol extracts of Piper chaba roots $(60-1000 \mu \mathrm{g} / \mathrm{ml})$. After incubation at 37 ${ }^{\circ} \mathrm{C}$ for $24 \mathrm{~h}$, plates were washed with distilled water to remove the free-floating cells. The biofilm was stained with $0.4 \%$ crystal violet (Himedia, Mumbai, India) solution. After $15 \mathrm{~min}$, the staining process was complete and distaining process started with $1 \mathrm{ml}$ of $95 \%$ ethanol. Finally, absorbance (at $650 \mathrm{~nm}$ ) was measured by using a multiplate ELISA reader (Biotek-ELX-800, India). Formation of biofilm was determined by using the following equation:

$\%$ of reduction of $\mathrm{OD}=$ Absorbance of (control-test) $/$ Absorbance of control $\times 100$

\section{Statistical analysis}

All data reported are presented as mean \pm SD or \pm SEM. Statistical analysis was performed by using one-way analysis of variance (ANOVA) with multiple comparison tests, where applicable. The difference between two groups was measured by the student $t$-test. A P-value less than $<0.05$ was considered statistically significant.

\section{RESULTS}

\section{Determination of four different RE of $P$. chaba on FBG level in STZ-} induced diabetic rats

The effect of EtOH-, MeOH-, EtOAc-, and AQ extract of the roots of $\mathrm{P}$. chaba were tested on the FBG levels in non-diabetic and diabetic rats on Day 0 and Day 21 and are shown in fig. 1. The FBG levels of the STZinduced diabetic control (DC, Gr-2) were significantly $(p<0.001)$ higher than those of the respective non-diabetic control (NDC, Gr-1) tested both on Day 0 and Day 21 group of animals and the FBG level remained high in Gr-2 through Gr-7 tested on Day 0. However, as measured by one-way ANOVA, pretreatment of a single dose of $200 \mathrm{mg} / \mathrm{kg} \mathrm{b}$. w RE exhibited a significant hypoglycemic effect $(p<0.001)$ tested on Day 21 , when compared to DC. Metformin, a standard hypoglycemic drug, also had a significant $(\mathrm{p}<0.001)$ reduction in FBG level in Gr-3. Also, an intra-group analysis as measured by t-test, the FBG level revealed a significant $(p<0.001)$ difference between Day 0 and Day 21 of each group (Gr-2 to Gr-7) (fig. 1).

\section{Evaluation of different REs of $P$. chaba on lipid profiles in STZ-} induced diabetic rats

Diabetes is also associated with altered lipid profile. The effect of $\mathrm{EtOH}-, \mathrm{MeOH}-, \mathrm{EtOAc}$, and $\mathrm{AQ}$ extract of the roots of $P$. chaba were tested on the serum levels of LDL, HDL, TC, and TG in STZ-induced diabetic Wister rats (fig. 2 and fig. 3). 


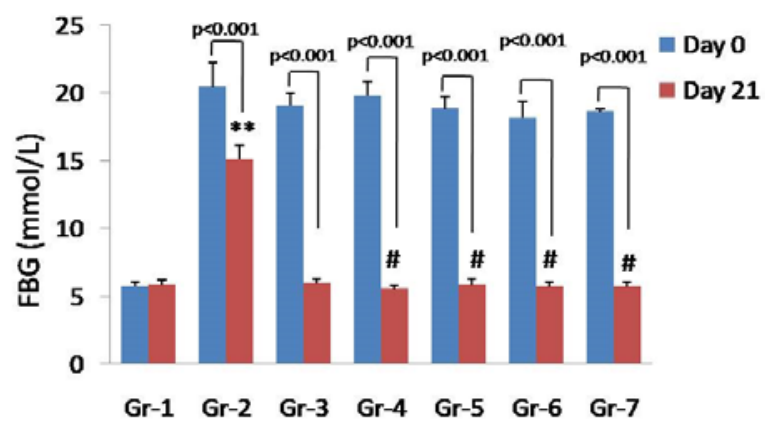

Fig. 1: Fasting blood glucose (FBG) level in normal and STZ-induced diabetic rats. $n=5$; Data are means $\pm S D$. ${ }^{* *} \mathbf{p}<0.001$, versus respective control (Gr1); \#p<0.001, versus respective DC (Gr-2). The difference between the groups on day 21 was analyzed by one-way ANOVA followed by Bonferroni post hoc test and the difference between Day 0 and Day 21 of the same group was analyzed by t-test and the p value is shown inside the figure. Gr-1: nondiabetic control rats treated with standard diet (SD); Gr-2: STZ-induced diabetic rats treated with SD (negative control); Gr-3: Diabetic rats treated with SD and metformin (positive control); Gr-4: Diabetic rats treated with SD and ethanol extracts (200 mg/kg. b.w. in a day); Gr-5: Diabetic rats treated with SD and methanol extracts $(200 \mathrm{mg} / \mathrm{kg}$. b.w. in a day); Gr-6: Diabetic rats treated with SD and ethyl acetate extracts (200 mg/kg. b.w. in a day); Gr-7: Diabetic rats treated with SD and aqueous extracts $(200 \mathrm{mg} / \mathrm{kg}$. b.w. in a day). $\mathrm{n}=$ number of experimental animals.

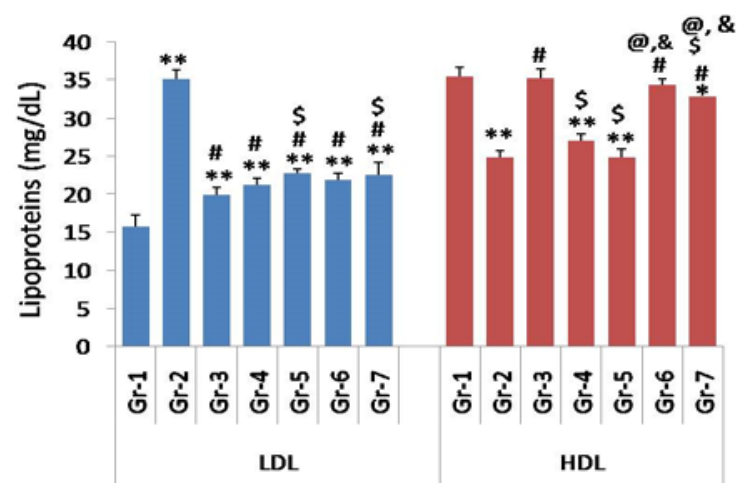

Fig. 2: Effect of Piper chaba root extracts on lipoproteins (LDL and HDL) in normal and STZ-induced diabetic rats after $20 \mathrm{~d}$ treatment. Values are presented as mean \pm standard deviation of the mean; $n=6 ; p^{*}<0.05$, ${ }^{* *} p<0.001$, versus $\mathrm{Gr}-1 ; \# p<0.001$, versus $\mathrm{Gr}-2 ; \$ p=0.002$, versus $\mathrm{Gr}-3$; $\# p<0.001$ versus Gr-2; @p $<0.001$, versus Gr-4; andp <0.001, versus Gr-5. Gr-1: non-diabetic control rats treated with standard diet (SD); Gr-2: STZinduced diabetic rats treated with SD (negative control); Gr-3: Diabetic rats treated with SD and metformin (positive control); Gr-4: Diabetic rats treated with SD and ethanol extracts $(200 \mathrm{mg} / \mathrm{kg}$. b.w. in a day); Gr-5: Diabetic rats treated with SD and methanol extracts (200 mg/kg. b.w. in a day); Gr-6: Diabetic rats treated with SD and ethyl acetate extracts (200 mg/kg. b.w. in a day); Gr-7: Diabetic rats treated with SD and aqueous extracts $(200 \mathrm{mg} / \mathrm{kg}$. b.w. in a day). $\mathrm{n}=$ number of experimental animals

The STZ-induced diabetic control (DC, Gr-2) significantly elevated the serum level of LDL $(\mathrm{p}<0.001), \mathrm{TC}(\mathrm{p}<0.001)$, and TG $(\mathrm{p}<0.001)$, but reduced the level of HDL ( $\mathrm{p}<0.001)$, as compared to non-diabetic control (NDC, Gr-1, fig. 2). Metformin-treated diabetic rats (Gr-3) significantly reduced the levels of LDL $(p<0.001)$, TC $(p<0.001)$, and TG $(p<0.001)$, when compared with the DC. However, as compared to DC, metformintreated diabetic rats $(\mathrm{Gr}-3)$ significantly $(\mathrm{p}<0.001)$ increased the level of HDL and showed no difference on the level of HDL, when compared with the NDC. Changes in serum lipids concentration following different REtreatments were also evaluated as shown in fig. 2 and fig. 3 .

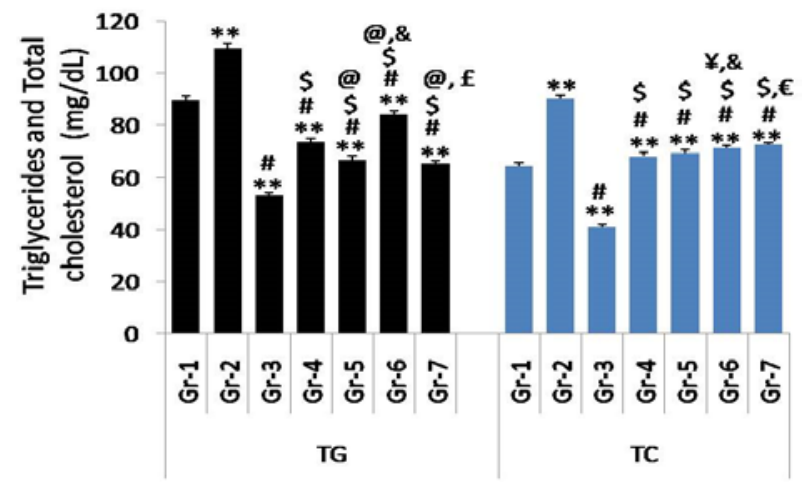

Fig. 3: Effect of Piper chaba root extracts on Lipoproteins (LDL and HDL) in normal and STZ-induced diabetic rats after $20 \mathrm{~d}$ treatment. Values are presented as mean \pm standard deviation of the mean; $n=6 ; p^{*}<0.05$, ${ }^{* *} p<0.001$, versus $\mathrm{Gr}-1$; \#p $<0.001$, versus $\mathrm{Gr}-2$; \#p $<0.001$ versus $\mathrm{Gr}-2$; $\$ p<0.001$, versus Gr-3; ¥p<0.01,@p<0.001, versus Gr-4; $€ p<0.01$, andp $<0.001$, versus Gr-5; $€<p 0.001$, versus Gr-6. Gr-1: non-diabetic control rats treated with standard diet (SD); Gr-2: STZ-induced diabetic rats treated with SD (negative control); Gr-3: Diabetic rats treated with SD and metformin (positive control); Gr-4: Diabetic rats treated with SD and ethanol extracts $(200 \mathrm{mg} / \mathrm{kg}$. b.w. in a day); Gr-5: Diabetic rats treated with SD and methanol extracts $(200 \mathrm{mg} / \mathrm{kg}$. b.w. in a day); Gr-6: Diabetic rats treated with SD and ethyl acetate extracts (200 mg/kg. b.w. in a day); Gr-7: Diabetic rats treated with SD and aqueous extracts $(200 \mathrm{mg} / \mathrm{kg}$. b.w. in a day). $\mathrm{n}=$ number of experimental animals 
Treatments with extracts of EtOH, $\mathrm{MeOH}$, EtOAc, and $\mathrm{AQ}$ extracts showed a significant $(\mathrm{p}<0.001)$ decrease in LDL, TC, and TG when compared with DC. On the contrary, EtOAc, and AQ extracts, but not $\mathrm{EtOH}, \mathrm{MeOH}$ extracts, showed a significant $(\mathrm{p}<0.001)$ increase in HDL level, as compared with DC.

\section{Determination of antimicrobial activity}

Two extracts (methanol and ethyl acetate) represented varying antimicrobial activities in this study (table 1). The zone of inhibition (ZOI) against gram negative bacteria was bigger than that of gram positive bacteria. Susceptibility of these two extracts against bacteria increased with the increase in concentrations. Other two extracts (ethanol and aqueous) showed no antimicrobial activity.

\section{Effect of Piper chaba extracts on the formation of bacterial biofilm}

Ethyl acetate and methanol extracts showed antimicrobial activity against Escherichia coli (table 1). Effect of these extracts on biofilm produced by the same bacteria was also checked. It was observed that ethyl acetate and methanol extracts dose-dependently inhibited the formation of biofilm when applied in increasing concentrations $(60,125,250,500,1000$ and $1200 \mu \mathrm{g} / \mathrm{ml})$. SEM was calculated from three independent experiments. Comparing to the control, administration of ethyl acetate and methanol extract reduced the formation of biofilm from 3 to $13 \%$ and 2 to $5 \%$, respectively. Percentage of inhibition became highest at a concentration of 1000 $\mu \mathrm{g} / \mathrm{ml}$ and become almost constant at $1200 \mu \mathrm{g} / \mathrm{ml}$ (fig. 4).

Table 1: Antibacterial activity of different extracts of the roots of Piper chaba

\begin{tabular}{|c|c|c|c|c|c|c|c|c|c|}
\hline \multicolumn{10}{|c|}{ Diameter of zone of inhibition (mm) } \\
\hline \multicolumn{3}{|c|}{ Ethyl acetate $(\mu \mathrm{g} /$ disc $)$} & \multicolumn{2}{|c|}{ Methanolic $(\mu \mathrm{g} /$ disc $)$} & \multicolumn{2}{|c|}{ Ethanolic $(\mu \mathrm{g} /$ disc) } & \multicolumn{2}{|c|}{ Aqueous ( $\mu \mathrm{g} /$ disc) } & Kanamycin $(\mu \mathrm{g} /$ disc $)$ \\
\hline Bacteria & 200 & 400 & 200 & 400 & 200 & 400 & 200 & 400 & $30 \pm 0.1$ \\
\hline Bacillus cereus & $09 \pm 0.5$ & $12 \pm 0.43$ & $08 \pm 0.35$ & $11 \pm 0.6$ & Nil & Nil & Nil & Nil & $29 \pm 0.05$ \\
\hline Escherichia coli & $10 \pm 0.31$ & $15 \pm 0.12$ & $10 \pm 0.25$ & $14 \pm 0.51$ & Nil & Nil & Nil & Nil & $29 \pm 0.07$ \\
\hline
\end{tabular}

Values are expressed as mean \pm SD $(n=3)$. $n=$ number of experiments.

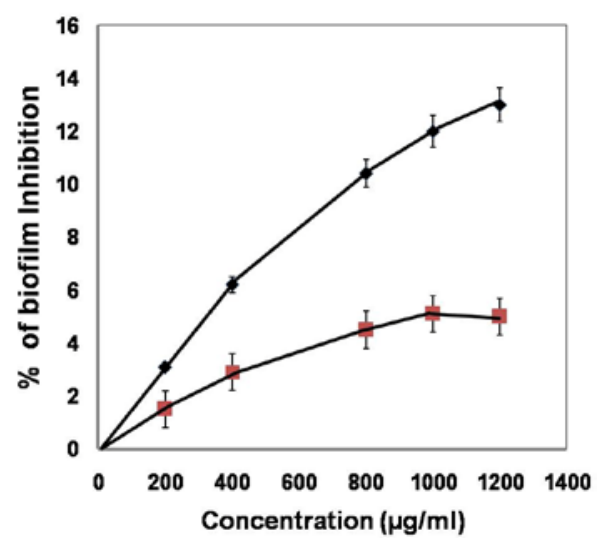

Fig. 4: Antibiofilm activity of root extracts of Piper chaba. Black and orange boxes denote ethyl acetate and methanol extracts, respectively. Values are expressed as mean $\pm \mathrm{SEM}$; ${ }^{*} \mathbf{P}<0.05$ was considered to be significant with respect to the control group

\section{DISCUSSION}

The present investigation discusses the antidiabetic and antihyperlipidemic potential of the RE of $P$. chaba in STZ-induced diabetic rats. DM is a chronic metabolic disorder. Vascular complications are among the most common sequela of the condition, as cardiovascular disease accounts for $65 \%$ of mortality in DM [21]. Our study evaluated the effect of EtOH-, $\mathrm{MeOH}-$, EtOAc-, and AQ extracts of the roots of $P$. chaba on STZ-induced diabetic rats. STZ, an $\mathrm{N}$-acetyl glucosamine analogue, was used in our study to induce DM in rats. It destroys pancreatic $\beta$-cells by donating nitric oxide (NO), but has no effect on the exocrine part of pancreases [22].

Our short-term study confirmed the reducing effect of oral administration of $P$. chaba RE at a dose of $200 \mathrm{mg} / \mathrm{kg}$ b.w. on FBG level in diabetic rats significantly and the values of RE-treated rats after $21 \mathrm{~d}$ of treatment came to the level of the non-diabetic control rats. A similar outcome at the same dose after $30 \mathrm{~d}$ treatment of root aqueous extract was reported by $P$. longum [16] The results of our study was also supported by the leaf extracts of $P$. guineense and $P$. auritum administered in diabetic female and male albino Wister rats, respectively $[23,24]$.

The recent studies have shown the increasing trends for the involvement of reactive oxygen species (ROS) and oxidative stress in the pathogenesis and development of type 2 DM [26]. A number of important phytoconstituents such as dimeric alkaloids and alkamides have been isolated from various parts of $P$. chaba [27]. Earlier, many researchers have shown that $P$. longum and $P$. chaba extracts from different parts of the plant contain several phytochemicals and bioactive compounds like piperine, saponin, and sesquiterpene hydrocarbons $\beta$-caryophyllene, $\alpha$-humulene and germacrene D having their antioxidant properties $[28,29]$, that possibly scavenge free radicals too. On the other hands, the protein glycation and advanced glycation end products (AGEs) formation are associated with DM, which was also inhibited by the methanolic extract of $P$. betle and $P$. auritum leaves [30].

DM has been generally seen to have strong association with hyperlipidemia. The development of marked hyperlipidemia in diabetes may be a consequence of the uninhibited actions of lipolytic hormones on the fat depots and increase in mobilization of fatty acids from fat tissue [31]. In our investigation, we have observed the diabetic hyperlipidemia as marked with enhanced TG, TC, LDL, but decreased HDL cholesterol level. However, in STZ-induced diabetic rats, all four RE of $P$. chaba at a dose $200 \mathrm{mg} / \mathrm{kg}$ b.w. in our findings significantly reduced the level of TG, TC, and LDL, but increased the level of HDL when treated with EtOAc and AQ extracts. The LDL and HDL are considered as more particular and sensitive biochemical markers of cardiovascular disease. A thorough literature searches on hypolipidemic effect of the extracts of other species of the Piper genus also hold up our findings. In rabbits, the ethanolic fruit extract of $P$. chaba $(150 \mathrm{mg} / \mathrm{kg})$ possessed significant hypolipidemic effects and lowered TC and LDL levels while showing significant effect on HDL levels as well. Whereas, $P$. nigrum fruit extract $(250 \mathrm{mg} / \mathrm{kg})$ significantly elevated the levels of cholesterol and HDL and lowered LDL level on albino rabbits [32]. Also, other two different studies using the methanol and ethanol leaf extracts of $P$. betel at the dosages of 250 $\mathrm{mg} / \mathrm{kg} \mathrm{b.} \mathrm{w}$ and $500 \mathrm{mg} / \mathrm{kg} \mathrm{b}$. w, respectively, on male albino Wister rats showed significant reduction of TC, TG, LDL and VLDL and HDL level became augmented [33]. It was suggested that the piperidine alkaloids including piperine, pipernonaline and dehydropipernonaline could be responsible for producing this effect by activating AMPactivated protein kinase that regulate lipid metabolism [34]. Our results following the same trend suggest that $P$. chaba REs can turn down the risk of diabetes-induced cardiovascular diseases by decreasing serum TC, TG and LDL levels and increasing serum HDL levels. The increased level of HDL is very significant due to its ability to reversely transport cholesterol from peripheral tissue and to esterifies cholesterol by lecithin-cholesterol acyltransferase (LCAT) [35]. So, the effect of P. chaba RE in diabetic disorder is remarkable.

Medicinal plants have been traditionally used for treatments against various bacteria. The antimicrobial activity of piper chaba root extracts showed dose-depended nature against Bacillus cereus (gram positive) 
and Escherichia coli (gram negative). Our result showed the highest activity against gram negative bacteria and similar results have been found in previous studies [36]. It probably happened due to the presence of biologically active compounds such as phenolic, flavonoids, polyphenols, isoprenoids, alkaloids etc. in plant extracts and their effects on the cell wall components of bacteria. Structural and compositional difference in cell wall and cell membrane of gram positive and gram negative bacteria also plays a role [37-39]. An earlier study discovered a relationship between the antimicrobial activity and phytochemicals present in medicinal plants extract [40].

Our result suggested that the root extract was more active against gram negative microorganisms than gram positive microorganisms. E. coli are gram negative bacteria and have the ability to form biofilm $[41,42]$. The antimicrobial activity of our plant (ethyl acetate and methanolic) extracts against gram negative bacteria encouraged us to investigate the properties of antibiofilm properties of these extracts. From our study it became evident that $200 \mu \mathrm{g} / \mathrm{ml}$ and 1000 $\mu \mathrm{g} / \mathrm{ml}$ were the minimum and maximum concentrations of extracts to inhibit the formation of biofilm. Pronounced biofilm inhibition ability was found in ethyl acetate and also in methanol extracts. Similar result with solvent depended extracts of $P$. longum and $P$. nigrum were observed against Streptococcus pyogenes at the lowest concentration of $500 \mu \mathrm{g} / \mathrm{ml}$ [43]. Promising antibiofilm activity was observed in case of methanolic crude extract of $P$. longum against Vancomycine-resistant $S$. aureus-pAR1818 and S. aureus MH4 and MTCC 96 isolates whereas ethanol extracts of Piper longum fruits could reduce the cell attachment and inhibit the formation of biofilm by Staphylococcus aureus at $500 \mu \mathrm{g} / \mathrm{ml}[44,45]$. Walmiki et al., found that Piper nigrum possessed antibiofilm activity against Escherichia coli and Salmonella spp [46].

\section{CONCLUSION}

The present findings, for the first time, demonstrated that the RE of $P$. chaba is capable of exhibiting significant antihyperglycemic and antihyperlipidemic activities in STZ-induced diabetic rats. Moreover, the extract increased the level of HDL, a protective lipid compound, in diabetic condition. Therefore, our results give scientific support for the use of this plant in traditional medicine for the management of diabetes and its associated complications though further molecular studies are required to investigate the mechanism underlying the antihyperglycemic and antihyperlipidemic effect of $P$. chaba REs. Moreover, marked antimicrobial and antibiofilm activities of these extracts have also been observed.

\section{ACKNOWLEDGEMENT}

We are grateful to Professor Dr. Ekramul Islam, Ex-Coordinator, Department of Pharmacy, VU, for his support to use the Laboratory at the Department of Pharmacy, VU. Also, we appreciate the efforts of Mr. Robiul Islam, Executive-Lab, Department of Pharmacy, VU, for providing technical support.

\section{FUNDING}

The research was supported by Varendra University Trust (VUT)sponsored Faculty Research Grant 2019 at the Center for Interdisciplinary Research (CIR), VU, Rajshahi, Bangladesh.

\section{AUTHORS CONTRIBUTIONS}

SR did the majority of the study and wrote the manuscript. KK, UF and SoR were involved in experimental works and data analysis. $\mathrm{RH}$ provided laboratory support, supervised the study and improved the manuscript through careful review and helpful suggestions.

\section{CONFLICT OF INTERESTS}

Authors declare no conflict of interest with respect to the research reported herein.

\section{REFERENCES}

1. Ghani A. Medicinal plants of Bangladesh with chemical constituents and uses. 2nd ed. Dhaka, Asiatic Society of Bangladesh; 2003. p. 1-16.

2. Muchuweti M, Kativu E, Mupure $\mathrm{CH}$, Chidewe $\mathrm{C}$, Ndhlala AR, Benhura MA. Phenolic composition and antioxidant properties of some spices. Am J Food Technol 2007;2:414-20.
3. Kannadhasan R, Venkataraman S. Antidiabetic and antihyperlipidaemic activity of sedimental extract of Tinospora cordifolia in streotozotocin-induced type 2 diabetes. Int J Pharm Pharm Sci 2012;4 Suppl 3:520-7.

4. Wicaksono BD, Handoko YA, Arung ET, Kusuma IW, Yulia D, Pancaputra AN, et al. Antiproliferative effect of the methanol extract of Piper crocatum ruiz and pav leaves on human breast (T47D) cells in vitro. Trop J Pharm Res 2009;8:345-52.

5. Sunila ES, Kuttan G. Immunomodulatory and antitumor activity of piper longum linn. and piperine. J Etanopharmacol 2004;90:339-46.

6. Shelke DP, Swamy VSM. Medicinal plants for diabetes mellitus: a review. Asian J Pharm Clin Res 2021;14:45-8.

7. Haque R, Iuvone PM, He L, Choi KSC, Ngo A, Gokhale S, et al. The microRNA-21 signaling pathway is involved in prorenin receptor (PRR)-induced VEGF expression in ARPE-19 cells under a hyperglycemic condition. Mol Vis 2017;23:251-62.

8. Kavitha KN, Dattatri AN. Experimental evaluation of antidiabetic activity of Swertia chirara-aqueous extract. J Pub Health Med Res 2013;1:71-5.

9. IDF Diabetes Atlas. Ninth Ed; 2019. Available from: www.diabetesatlas.org. [Last accessed on 10 Apr 2021]

10. Web World Health Rankings. Bangladesh: Diabetes Mellitus. Available from: https://www.worldlifeexpectancy.com/ bangladesh-diabetes-mellitus. [Last accessed on 10 Apr 2021]

11. Kumar P, Clark M. Diabetes mellitus and other disorders of metabolism. In: Sunders WB. (Eds) Clinical medicine. $2^{\text {nd }}$ ed. London: Elsevier; 2013. p. 1069-71.

12. Lorenzati B, Zucco C, Miglietta S, Lamberti F, Bruno G. Oral hypoglycemic drugs: pathophysiological basis of their mechanism of action. Pharmaceuticals 2010;3:3005-20.

13. Rao MN, Sreenivasulum M, Chengaiah B, Reddy J, Chetty CM. Herbal medicines for diadetes mellitus: a review. Int J Pharm Tech Res 2010;2:1883-92.

14. World Health Organization. WHO guidelines for the assessment of herbal medicine. WHO Expert Committee on specification for pharmaceutical preparation. Technical Report 1996;863:97-108.

15. Hasibuan MS, Yasni S, Bintang M, Ranti AS. Antihyperglycemic activity of Piper crocatum leaves and Cinnamomum burmannii bark mixture extract in streptozotocin-induced diabetic rats. J Math Fund Sci 2013;48:178-91.

16. Nabi SA, Kasetti RB, Sirasanagandla S, Tilak TK, Kumar MV, Rao CA. Antidiabetic and antihyperlipidemic activity of Piper longum root aqueous extract in STZ induced diabetic rats. BMC Complement Altern Med 2013;13:37.

17. Kaleem M, Sheema, Sarmad H, Bano B. Protective effects of piper nigrum and vinca rosea in alloxan induced diabetic rats. Indian J Physiol Pharmacol 2005;49:65-71.

18. Truong DH, Nguyen DH, Ta NTA, Bui AV, Do TH, Nguyen HC. Evaluation of the use of different solvents for phytochemical constituents, antioxidants, and in vitro anti-inflammatory activities of Severinia buxifolia. J Food Qual 2019;2019:9.

19. Guide for the care and use of laboratory animals (Eighth Edition) published by The national academies press: 2101 Constitution Ave NW, Washington DC 20055, USA; 2011.

20. Hasan I, Ozeki Y, Kabir SR. Purification of a novel chitin-binding lectin with antimicrobial and antibiofilm activities from a Bangladeshi cultivar of potato (Solanum tuberosum). Ind J Biochem Biophys 2014;51:142-8.

21. Farbstein D, Levy AP. Pharmacogenomics and the prevention of vascular complications in diabetes mellitus. Therapy 2009;6:531-8.

22. Raza H, John A. Streptozotocin-induced cytotoxic, oxidative stress and mitochondrial dysfunction in human hepatoma HepG2 cells. Int J Mol Sci 2012;13:5751-67.

23. Wodu CO, Iwuji SC, Adienbo OM. Antihyperglycemic activity of Piper guineense in diabetic female albino wistar rats. Int J Pharm Phytopharmacol Res 2014;7:1-4.

24. Gonzalez AMN, Gutierrez RMP, Cotera LBF. Antidiabetic activity of piper auritum leaves in streptozotocin-induced diabetic rat, beficial effect on advanced glycation endproduct. Chin J Integr Med 2014. DOI:10.1007/s11655-014-1753-2.

25. Jawaid T, Argal S, Kamal M. Antidiabetic and antihyperlipidemic effcets of the ethanolic extract of alocasia indica rhizomes in high 
fat diet/streptozotocin and streptozotocin/nicotinamide-induced type 2 diabetic rats. Asian J Pharm Clin Res 2015;8:58-62.

26. Rehman K, Akash MSH. Mechanism of generation of oxidative stress and pathophysiology of type 2 diabetes mellitus: how are they interlinked? J Cell Biochem 2017;118:3577-85.

27. Islam MT, Hasan J, Snigdha HMSH, Ali ES, Sharifi-Rad J, Martorell M, et al. Chemical profile, traditional uses, and biological activities of piper chaba Vahl: A review. J Ethnopharmacology 2020;257:112853.

28. Islam MS, Roy AC, Haque MM, Hossain MS, Sayeed MA Phytochemical studies on Piper chaba hunter. Int J Pharm Sci Res 2015;6:2525-31.

29. Rameskumar KB, Aravind AP, Mathew PJ. Comparative phytochemical evalution and antioxident assay of Piper Longum L. and Piper Chaba hunter used in Indian traditional systems of medicine. J Herbs Spices Med Plants 2011;17:351-60.

30. Bhattacherjee A, Chakraborti AS. Inhibitory effect of Piper betle Linn. leaf extract on protein glycation--quantification and characterization of the antiglycation components. Indian J Biochem Biophys 2013;50:529-36.

31. Nagmoti DM, Kothavade PS, Bulani VD, Gawali NB, Juvekar AR. Antidiabetic and antihyperlipidemic activity of Pithecellobium dulce (Roxb.) benth seeds extract in streptozotocin-induced diabetic rats. Eur J Integr Med 2015;7:263-73.

32. Sarfaraz S, Najam R, Azhar I, Sarwar G. Comparative evaluation of hypolipidemic effects of ethanolic extract of fruit of Piper Chaba and Piper Nigrum on albino rabbits. J Forensic Biomech 2016;7:1-4.

33. Venkadeswaran K, Muralidharan AR, Annadurai T, Ruban VV. Antihypercholesterolemic and antioxidative potential of an extract of the plant, Piper betle, and its active constituent, eugenol, in triton WR-1339-induced hypercholesterolemia in experimental rats. Evid Based Complement Alternat Med 2014;2014:478973.

34. Kim KJ, Lee MS, Jo K, Hwang JK. Piperine alkaloids from piper retrofractum vahl. protect against high-fat diet-induced obesity by regulating lipid metabolism and activating AMP-activated protein kinase. Biochem Biophys Res Commun 2011;411:219-25.

35. Pochhi M. Evalution of antidiabetic potential and hypolipidemic activity of Coccinia indica (leaves) in diabetic albino rats. Asian J Med Sci 2019;10:49-54.
36. Kanboj A, Kuma S, Kumar V. Evaluation of antidiabetic activity of hydroalcoholic extract of Cestrum nocturnum leaves in streptozotocin-induced diabetic rats. Adv Pharmacol Sci 2013;1-4. DOI:10.1155/2013/150401

37. Trivedi MN, Khemani A, Vachhani UD, Shah CP, Santani DD. Pharmacognostic, phytochemical analysis and antimicrobial activity of two Piper species. Int J Compr Pharm 2011;2:1-4.

38. Cowan MM. Plant products as antimicrobial agents. Clin Microbiol 1999;12:564-82.

39. Zacchino SA, Butassi E, Liberto MD, Raimondi M. Plant phenolics and terpenoids as adjuvants of antibacterial and antifungal drugs. Phytomedicine 2017;37:27-48.

40. Zuo GY, Yang CX, Han J, Li YQ. Synergism of prenylflavonoids from Morus alba root bark against clinical MRSA isolates. Phytomedicine 2018;39:93-9.

41. Chakraborty S, Dutta T, De A, Das M. Impact of bacterial biofilm in veterinary medicine: an overview. Int J Curr Microbiol Appl Sci 2018;7:3228-39.

42. Petruzzi B, Dalloul RA, LeRoith T, Evans NP. Biofilm formation and avian immune response following experimental acute and chronic avian cholere due to pasteurella multacida. Vet Microbiol 2018;222:114-23.

43. Darsini DTP, Srinivasan P, Guna G, Manimekalai K. In vitro anti biofilm activity of Piper longum and Piper nigrum against clinical isolates of Streptococcus pyogenes isolated from pharyngitis patients. Int Res J Pharm 2015;6:122-32.

44. Everlyne IM, Darsini DTP, Kulandhaivel M, Srinivasan P. Antibiofilm activity of Piper longum ethanol extract against methicillin resistant Staphylococcus aureus strains. Int J Curr Res 2015;7:17030-5.

45. Kumar V, Shriram V, Mulla J. Antibiotic resistance reversal of multiple drug resistant bacteria using Piper longum fruit extract. J Appl Pharm Sci 2013;3:112-6.

46. Walmiki MR, Rai VR. Cell attachment inhibition and antibiofilm activity of Syzygium aromaticum, Cuminum cyminum and Piper nigrum essential oils against pathogenic bacteria. J Essent Oil Bear Plants 2017;20:59-68. 